\title{
Editorial: Seafloor Mapping of the Atlantic Ocean
}

\author{
Pål Buhl-Mortensen ${ }^{1 *}$, Vincent Lecours ${ }^{2}$ and Craig J. Brown ${ }^{3}$ \\ ${ }^{1}$ Benthic Communities and Coastal Interactions Research Group, Institute of Marine Research (IMR), Bergen, Norway, \\ ${ }^{2}$ School of Forest, Fisheries, and Geomatics Sciences, University of Florida, Gainesville, FL, United States, ${ }^{3}$ Department of \\ Oceanography, Dalhousie University, Halifax, NS, Canada
}

Keywords: seafloor bathymetry, seafloor mapping, benthic habitats, seascape ecology, habitat mapping, marine geology, marine geomorphology

\section{Editorial on the Research Topic}

\author{
Seafloor Mapping of the Atlantic Ocean
}

\section{THE IMPORTANCE OF SEAFLOOR MAPPING}

Patricio Bernal, the Coordinator of the International Union for Conservation of Nature High Seas Initiative, once wrote: "We know more about the surface of the Moon and about Mars than we do about the deep seafloor, despite the fact that we have yet to extract a gram of food, a breath of oxygen or a drop of water from those bodies" (Snelgrove, 2010). Often referred to as the last frontier on Earth, the deep seafloor is thought to shelter both critical ecosystems and exploitable resources (i.e., minerals, bio-active natural products, and genetic material, in addition to food resources already being harvested by the fishing industry). These resources are said to have enormous potential to contribute to the growth of the blue economy, potential that will be realized only with an increased understanding of deep-sea environments (Glover et al., 2018). However, knowledge of deep-sea environments and the anthropogenic impacts on them lags in comparison to other marine environments. To address this issue, several cooperative international agreements have been signed. For instance, the Galway Statement (signed by the European Union, United States, and Canada) and the Belém Statement (also signed by Brazil and South Africa) were endorsed to launch an All-Atlantic Ocean Research Alliance. This alliance aims to increase our understanding of the Atlantic Ocean and its systems and promote the sustainable management of its resources. In addition, activities and programs associated with the United Nations Decade of Ocean Science for Sustainable Development (2021-2030), such as The Nippon Foundation-GEBCO Seabed 2030 Project, Challenger 150, and the One Ocean Network for Deep Observation, will likely help increase awareness of the importance of seafloor mapping.

The efforts involved in mapping the seafloor, its habitats, and its resources require the adoption of an interdisciplinary perspective, working across fields such as marine geology, geomorphology, oceanography, biology, ecology, underwater acoustics, geomatics, and more. While the technologies to map the physical and biological components of the deep seafloor exist, the financial, human, and material resources required to collect data at a spatial resolution that is adequate for conservation and management purposes are currently limiting the scope of the work that could be achieved (Danovaro et al., 2020). There have been significant technological and methodological developments in recent years, some of which are presented in this Research Topic.

This Research Topic showcases contributions addressing all aspects of the marine sciences that introduce new knowledge and new approaches to improve our understanding of the characteristics of the Atlantic Ocean. Three themes central to seafloor mapping are covered: (1) the spatial settings of the environment (e.g., bathymetry, geomorphology, marine landscapes); (2) the abiotic 
environment (e.g., seafloor geology, oceanography, hydrodynamics, water chemistry); and (3) the biotic environment (e.g., benthic biodiversity, communities, habitats).

\section{STATE OF THE ART MAPPING APPROACHES}

Despite continued growth in marine habitat mapping technologies and methods, development is still needed to further our understanding of marine habitats and how they are explored; there is still no "standard recipe" for seafloor mapping studies. Seafloor mapping efforts can be categorized into different themes depending on their primary objective. The management and exploitation of living resources including fisheries, petroleum and mineral explorations, ecosystem conservation and restoration, navigation and maritime safety, and academic knowledge gathering are examples where different perspectives define the focus of what information is most relevant. A holistic description of the seafloor would require enormous efforts involving a multitude of equipment. Nonetheless, many studies now collect comprehensive suites of interdisciplinary data, as demonstrated in several studies presented in this Research Topic (e.g., Jovane et al.; Buhl-Mortensen et al.).

Multibeam echosounders are widely used for seafloor mapping, as reflected in this collection of articles; seven out of twelve articles used data collected with such instrument (e.g., Buhl-Mortensen et al.; Jovane et al.; Masetti et al.). Half of the contributions used at least one compiled dataset (e.g., GEBCO or EMODnet bathymetry) (e.g., Burgos et al.; Gonzales-Mirelis et al.; Ross et al.; Sundahl et al.), highlighting the importance of seafloor data compilation and integration efforts and making data available to increase their use and the potential for new scientific discoveries. This relates to the spatial scale of the research that is performed; six of the study areas presented in this Research Topic covered a broad geographic extent with broaderscale seafloor data (up to km-scale resolution) (e.g., Burgos et al.; Gonzales-Mirelis et al.), and the remaining contributions used finer-scale data (down to $\mathrm{cm}$-scale resolution) over smaller extents (e.g., Thorsnes et al.). There is also an interest in subseafloor geology; four articles (Alves et al.; Jovane et al.; Meredyk et al.; Thorsnes et al.) used instruments such as sub-bottom profilers or magnetometers to integrate structural elements of the seafloor.

Visual information about the seafloor has been gathered from remotely-operated vehicles (ROVs) (e.g., Meredyk et al.), towed video (e.g., Buhl-Mortensen et al.; Gonzalez-Mirelis et al.; Sundahl et al.), and Autonomous Underwater Vehicles (AUVs) (e.g., Thorsnes et al.). These observation platforms have their benefits and limitations where time consumption (cost), visual quality, and purpose of the survey are governing elements. Thorsnes et al. used an AUV as a platform for a multibeam echosounder, a synthetic aperture sonar, and digital photography. Over the last 20 years, the development of AUVs has increased their applications in local high-resolution bathymetry mapping and visual ground-truthing. However, due to limitations in battery power and steady maneuvering close to the bottom in rugged terrain, the quality of imagery collected with AUVs is still limited compared to imagery collected with ROVs.

To fully understand benthic ecosystems, studying the physiochemical properties of the water near the seafloor is essential. Many of the papers in the Research Topic have integrated chemical data (e.g., salinity and aragonite saturation) (e.g., Burgos et al.), near-bottom currents (e.g., Ross et al.), and temperature data (e.g., Sundahl et al.) with bathymetric and biological data. Even though these data are generally only available at a coarser resolution than the acoustic mapping and optical ground validation data, they are nonetheless valuable additional information for understanding benthic ecosystems and increasing the performance of species distribution models and habitat maps.

\section{CHALLENGES AND FUTURE DIRECTIONS}

The diversity of work done in habitat mapping strongly depends upon funding sources and funding opportunities. A comprehensive survey of seafloor habitats requires agencies or organizations willing to dedicate significant funds toward seafloor mapping. Most contributions (10 out of 12 papers) cover study areas within the Exclusive Economic Zones (EEZ) of countries in the North Atlantic, where several wellfunded seafloor mapping initiatives are active [e.g., Norway's MAREANO programme (Buhl-Mortensen et al., 2015; Bøe et al., 2020)]. This highlights a geographic bias in resource allocation toward EEZs, even though international waters account for about two-thirds of the global ocean. Only two papers represent the South Atlantic (Alves et al.; Jovane et al.). The North Atlantic studies are divided among the Caribbean Sea (Lavagnino et al.), North West Atlantic (Masetti et al.; Meredyk et al.; Sowers et al.), North East Atlantic (Buhl-Mortensen et al.; Sundahl et al.; Ross et al.; Burgos et al.; Gonzales-Mirelis et al.), and the Arctic Ocean (Buhl-Mortensen et al.; Burgos et al.; Gonzales-Mirelis et al.; Thorsnes et al.). Mapping efforts that cannot count on well-funded initiatives must rely on existing datasets rather than new data acquisition. Initiatives like The Nippon FoundationGEBCO Seabed 2030 Project (Mayer et al., 2018; Wölfl et al., 2019), an international effort to create a bathymetric map of the oceans by 2030, are helping to raise awareness about the importance of mapping waters beyond EEZs. Seafloor mapping in international waters is a global responsibility, and progress is being made as the number of initiatives and funding for such efforts is increasing.

Mapping the deep sea is time-consuming and costly as it covers vast areas that are challenging to sample. Thus, there is a strong motivation to develop new technologies and approaches to facilitate mapping and exploration. Crowd-sourced bathymetric data (e.g., Novaczek et al., 2019) and bycatch registration of invertebrates and fish are examples of alternative ways to collect data outside dedicated surveys. Commercial vessels may be equipped with relevant instruments and towed sensors that can increase data collection rate. Many existing datasets are not shared open access but are stored on local servers or as printed material, which hampers the progression of knowledge 
gathering for broader seafloor areas. The inclusion of such data in international data repositories is therefore critical.

Matching different spatial scales is a challenge for producing composite maps or understanding benthic ecosystems. While ground-truthing data are very fine-scale, acoustic data (bathymetry and backscatter) and other environmental data are usually collected at a coarser resolution. How we integrate such multiscale information remains unclear and is an active field of research (e.g., Misiuk et al., 2021). There is a tradeoff between the comprehensiveness of the environmental characterization and the level of detail provided: the inclusion of a broader-scale environmental dataset may constrain the analysis to a coarser resolution, potentially losing important information. By not including broader-scale datasets, analyses can be performed at higher spatial resolutions, but important patterns and processes may not be captured (Lecours et al., 2015).

Visual observations are commonly used to gather geological and biological seafloor information. Visual seafloor observations must be conducted within a visible range using subsea cameras, and increased efficiency of seafloor observation instruments like cameras and lights is needed. For AUVs to address this challenge, their maneuvering autonomy and optical quality must improve. Nevertheless, even with high-quality image, there remain limitations of visual data. For example, taxonomic identification of benthic fauna and accurate quantification of sediment grain size compositions remain challenging. For confident species identification, the sampling of specimens or material for genetic analysis is still needed. Analysis of subsea optical imagery

\section{REFERENCES}

Bøe, R., Bjarnadóttir, L. R., Elvenes, S., Dolan, M., Bellec, V., Thorsnes, T., et al. (2020). "Revealing the secrets of Norway's seafloor - geological mapping within the MAREANO programme and in coastal areas," in From Continental Shelf to Slope: Mapping the Oceanic Realm, eds K. Asch, H. Kitazato, and H. Vallius. Geological Society (London: Special Publications), 505. doi: 10.1144/SP505-2019-82

Buhl-Mortensen, L., Buhl-Mortensen, P., Dolan, M. F. J., and Holte, B. (2015). The MAREANO programme - a full coverage mapping of the Norwegian off-shore benthic environment and fauna. Mar. Biol. Res. 11, 4-17. doi: $10.1080 / 17451000.2014 .952312$

Danovaro, R., Fanelli, E., Aguzzi, J., Billet, D., Carugati, L., Corinaldesi, C., et al. (2020). Ecological variables for developing a global deepocean monitoring and conservation strategy. Nat. Ecol. Evol. 4, 181-192. doi: 10.1038/s41559-019-1091-z

Glover, A. G., Wiklund, H., Chen, C., and Dahlgren, T. G. (2018). Point of view: managing a sustainable deep-sea 'blue economy' requires knowledge of what actually lives there. eLife 7:e41319. doi: 10.7554/eLife.41319

Lecours, V., Devillers, R., Schneider, D. C., Lucieer, V. L., Brown, C. J., and Edinger, E. N. (2015). Spatial scale and geographic context in benthic habitat mapping: review and future directions. Mar. Ecol. Prog. Ser. 535, 259-284. doi: $10.3354 /$ meps 11378

Mayer, L., Jakobsson, M., Allen, G., Dorschel, B., Falconer, R., Ferrini, V., et al. (2018). The Nippon Foundation-GEBCO seabed 2030 project: the quest to see the world's oceans completely mapped by 2030 . Geosciences 8:63. doi: 10.3390/geosciences8020063

Misiuk, B., Lecours, V., Dolan, M. F. J., and Robert, K. (2021). Evaluating the suitability of multi-scale terrain attribute calculation and biological samples is also very time-consuming. The early applications of artificial intelligence are promising to support biological and geological data extraction from subsea imagery, interpreting geological and biological patterns, and modeling the spatial distribution of habitats and communities. As the field of seafloor mapping continues to grow, we look forward to the continued technical and methodological innovations that will result from these efforts.

\section{AUTHOR CONTRIBUTIONS}

PB-M introduced the idea for the Research Topic Seafloor Mapping of the Atlantic Ocean. PB-M, VL, and CB have revised and edited contributions to the Research Topic and contributed to the writing of this editorial. All authors contributed to the article and approved the submitted version.

\section{FUNDING}

This work was supported by AORA-CSA, Grant agreement ID: 652677.

\section{ACKNOWLEDGMENTS}

Thanks to colleagues in the Atlantic Ocean Research Alliance (EU project AORA-CSA). Also, thanks to Dr. Margaret Dolan at the Geological Survey of Norway (NGU), and Thomas Furey at the Marine Institute in Ireland for useful comments on this paper.

approaches for seabed mapping applications. Mar. Geodesy. 44, 327-385. doi: 10.1080/01490419.2021.1925789

Novaczek, E., Devillers, R., and Edinger, E. (2019). Generating higher resolution regional seafloor maps from crowd-sourced bathymetry. PLoS ONE 14:e0216792. doi: 10.1371/journal.pone.0216792

Snelgrove, P. V. R. (2010). Discoveries of The Census of Marine Life: Making Ocean Life Count. New York, NY: Cambridge University Press, 270.

Wölfl, A.-C., Snaith, H., Amirebrahimi, S., Devey, C. W., Dorschel, B., Ferrini, V., et al. (2019). Seafloor mapping - the challenge of a truly global ocean bathymetry. Front. Mar. Sci. 6:283. doi: 10.3389/fmars.2019.00283

Conflict of Interest: The authors declare that the research was conducted in the absence of any commercial or financial relationships that could be construed as a potential conflict of interest.

Publisher's Note: All claims expressed in this article are solely those of the authors and do not necessarily represent those of their affiliated organizations, or those of the publisher, the editors and the reviewers. Any product that may be evaluated in this article, or claim that may be made by its manufacturer, is not guaranteed or endorsed by the publisher.

Copyright (c) 2021 Buhl-Mortensen, Lecours and Brown. This is an open-access article distributed under the terms of the Creative Commons Attribution License (CC $B Y)$. The use, distribution or reproduction in other forums is permitted, provided the original author(s) and the copyright owner(s) are credited and that the original publication in this journal is cited, in accordance with accepted academic practice. No use, distribution or reproduction is permitted which does not comply with these terms. 